Pol. J. Food Nutr. Sci., 2020, Vol. 70, No. 3, pp. 291-300

DOI: $10.31883 /$ pjfns/124029 http://journal.pan.olsztyn.pl

Original research article

Food Quality and Functionality Section

\title{
Investigations of Volatile Organic Compounds in Berries of Different Actinidia kolomikta (Rupr. \& Maxim.) Maxim. Accessions
}

\author{
Laima Česonienè ${ }^{1 *}$, Remigijus Daubaras ${ }^{1}$, Sigita Bogačiovien $\dot{e}^{2}$, Audrius Sigitas Maruška ${ }^{2}$, \\ Mantas Stankevičius ${ }^{2}$, Andrius Valatavičius ${ }^{3}$, Marcin Zych $^{4}$, Sezai Ercisli ${ }^{5}$, Gulce Ilhan ${ }^{5}$
}

\author{
${ }^{I}$ Vytautas Magnus University, Botanical Garden, Z.E. Zilibero str. 2, LT-46324, Kaunas, Lithuania \\ ${ }^{2}$ Vytautas Magnus University, Instrumental Analysis Open Access Centre, Faculty of Natural Sciences, \\ Vileikos str. 8, LT-44404, Kaunas, Lithuania \\ ${ }^{3}$ Vilnius University, Institute of Mathematics and Informatics, Software Engineering Department, \\ Akademijos str. 4, Vilnius, LT-08663, Lithuania \\ ${ }^{4}$ University of Warsaw, Botanic Garden, Faculty of Biology, Aleje Ujazdowskie 4, 00-478 Warsaw, Poland \\ ${ }^{5}$ Ataturk University, Agricultural Faculty, Department of Horticulture, 25240, Erzurum, Turkey
}

Key words: berries, clone, cultivar, A. kolomikta, volatile compounds

The composition of volatile organic compounds contributes to fruit flavour and is an important element of fruit quality. Berries of sixteen cultivars and female clones of Actinidia kolomikta were studied by GC-MS with headspace solid phase microextraction method. In total, 89 compounds were separated and identified. These compounds were classified as terpenes, esters, alcohols, aldehydes, anhydrides, diazoles, hydrocarbons, and ketones. Among volatile organic compounds, esters were the most abundant. Significant differences in the diversity of volatile organic compounds were found among A. kolomikta cultivars and clones. Based on these results, we selected potential accessions for the breeding of new cultivars. Summarising the results of this study, the accessions of A. kolomikta were grouped according to the main flavour compounds.

\section{INTRODUCTION}

The taste of fruit is determined not only by the ratio between sugars and acids but also by a specific blend of different volatile components. There is an increasing interest in natural flavourings that may be used in food and nutraceutical products instead of synthetics [Henare, 2016]. Fruit volatile organic compounds (VOCs) represent a large group of chemical substances with a low molecular weight and a high vapour pressure under ambient conditions. In general, VOCs in fruits account for a very small part of the total weight [Dudareva et al., 2006; Jiang \& Song, 2010]. VOCs are released from different parts of plants and play an important role in plant interactions with the biological environment [Rodríguez et al., 2013]. The fruit flavour properties of different plant species and cultivars depend on the unique blend of VOCs [Jiang \& Song, 2010]. According to Negre-Zakharov et al. [2009], there are four major classes of VOCs, which are classified by their metabolic origin, namely, terpenoids, phenylpropanoids/benzenoids, fatty acids derivatives, and amino acid derivatives.

Within the genus Actinidia Lindl., various chemical substances determine the distinct flavour and the fragrance

\footnotetext{
* Corresponding Author: E-mail: laimac@hotmail.com (L. Česonienè) Other authors recorded ethyl butanoate and ethyl hexano-

of berries. The most comprehensive studies of VOCs in this genus were accomplished for cultivars of A. deliciosa (A.Chev.) C.F. Liang et A.R. Ferguson and A. chinensis Planch. There are numerous studies regarding the quantitative and qualitative characterisation of VOCs in kiwifruit [Cheng et al., 2011; Garcia et al., 2012b; Mota et al., 2012]. For example, over 80 volatile compounds were identified in $A$. deliciosa cultivar 'Hayward'. Interestingly, cultivars 'Hayward' and 'Hort16A' (A. chinensis) differ in only a few compounds and the specific aroma of their fruit is mainly attributable to the proportions of the VOCs [Wang et al., 2011]. Temporal variations in the VOC composition in kiwifruit depending on the harvest date were observed as well [Mota et al., 2012; Wang et al., 2011].

The characterization of bound volatile compounds of A. eriantha Benth. resulted in detection of major compound classes, i.e. alcohols, benzenoids, and phenolics. The precursors of bound compounds, including linoleic, linolenic and benzoic acids and coniferyl alcohol, were found as well [Garcia et al., 2012a]. Alcohols, terpenoids, and benzenoids classes were confirmed as the most abundant VOCs in A. arguta (Siebold \& Zucc.) Plant. ex Miq. [Garcia et al., 2011]. In this study, eugenol, raspberry ketone, and 4-vinylguaiacol were identified in berries of $A$. arguta for the first time. 
ate as the most abundant in A. arguta berries [Crowhurst et al., 2008]. Extracts of berries of the above-mentioned species contained different monoterpenes with such dominant esters as ethyl butanoate, hexanoate, 2-methylbutanoate, and 2-methylpropanoate, as well as the aldehydes: hexanal and hex-E2-enal [Matich et al., 2003]. In A. arguta berries, the intense fruity aroma was associated with high amounts of ethyl butanoate, whereas the floral aroma could be linked to other VOCs, i.e. methyl and ethyl benzoate [Lindhorst \& Steinhaus, 2016].

Berries of A. kolomikta (Rupr. \& Maxim.) Maxim. are an excellent source of biologically active compounds. They accumulate various organic acids, dietary fibres, carotenoids, minerals, flavonoids, and other valuable substances which determine their health-promoting properties [Latocha et al., 2010; Paulauskienè et al., 2014; Zuo et al., 2012]. The winter-hardy A. kolomikta accessions can be distinguished by higher amounts of ascorbic acid and phenolic compounds, and a higher antioxidant capacity from commercial A. chinensis and A. deliciosa cultivars [Chesoniene et al., 2004; Wang et al., 2018]. On the other hand, consumers prefer the delicious and aromatic berries of A. kolomikta for fresh consumption. This can be explained by the fact that $A$. kolomikta produces more palatable berries with green and edible skin [Chesoniene et al., 2004]. The role of VOCs of horticultural plants in their resistance to fungal and bacterial diseases or pests is of fundamental and practical interest. Yet, information on the qualitative and quantitative composition of VOCs in A. kolomikta is scarce. Another problem related with cultivation of $A$. kolomikta is the short shelf life of berries, which can be extended using edible polymer coatings or breeding more suitable cultivars [Drevinskas et al., 2017]. We hypothesised that $A$. kolomikta berries accumulate a variety of specific VOCs that could provide a pleasant berry aroma and (or) could be responsible for disease and pest resistance. Thus, the main aims of this study were: to determine the main groups of VOCs present in berries of different accessions of A. kolomikta and to determine composition of VOCs; as well as to compare the accessions of A. kolomikta in order to select these most suitable for consumption and also for the breeding of new cultivars.

\section{MATERIALS AND METHODS}

\section{Plant material}

A total of sixteen A. kolomikta accessions, including Lithuanian and Russian cultivars as well as female clones, were selected for investigations from the experimental collection of the Botanical Garden of the Vytautas Magnus University, Kaunas, Lithuania (Table 1). This collection is located in the central region of Lithuania (latitude $54^{\circ} 87^{\prime} 15^{\prime \prime} \mathrm{N}$ and longitude $23^{\circ} 91^{\prime} 08^{\prime \prime} \mathrm{E}$ ). The altitude of collection is $76 \mathrm{~m}$ above sea level. The average temperature is $15.9-17.8^{\circ} \mathrm{C}$ in July and $18.1-20.3^{\circ} \mathrm{C}$ in August. The average rainfall is 60 $-90 \mathrm{~mm}$ in July and 2-16 $\mathrm{mm}$ in August. The accessions were previously selected in this collection according to the different ripening time and berry weight [Chesoniene, 2000]. Characteristics of accessions investigated are presented in Table 1. At least three plants represented each accession.
TABLE 1. Characteristics of A. kolomikta accessions investigated in this study.

\begin{tabular}{|c|c|c|c|}
\hline $\begin{array}{l}\text { Cultivar or } \\
\text { female clone }\end{array}$ & Origin & $\begin{array}{c}\text { Ripening } \\
\text { time }\end{array}$ & $\begin{array}{c}\text { *Berry } \\
\text { weight, } \mathrm{g}\end{array}$ \\
\hline \multicolumn{4}{|c|}{ Cultivars } \\
\hline 'Landè' & Lithuania & early & $3.70 \pm 0.17^{\mathrm{b}}$ \\
\hline 'Lankè' & Lithuania & early & $1.87 \pm 0.07^{\mathrm{ij}}$ \\
\hline 'Anykšta' & Lithuania & late & $2.95 \pm 0.06^{\mathrm{d}}$ \\
\hline 'VIR- 1' & Russia & early & $2.61 \pm 0.05^{\mathrm{e}}$ \\
\hline 'VIR-2' & Russia & medium-early & $2.41 \pm 0.14^{\mathrm{ef}}$ \\
\hline 'Sentiabrskaja' & Russia & late & $2.28 \pm 0.07^{\mathrm{fg}}$ \\
\hline 'Krupnoplodnaja' & Russia & early & $4.22 \pm 0.10^{\mathrm{a}}$ \\
\hline 'Matovaja' & Russia & early & $2.37 \pm 0.11^{\mathrm{ef}}$ \\
\hline 'Aromatnaja' & Russia & early & $1.97 \pm 0.15^{\mathrm{ij}}$ \\
\hline 'Pavlovskaja' & Russia & early & $3.77 \pm 0.13^{b}$ \\
\hline 'Paukštės Šakarva' & Lithuania & early & $3.26 \pm 0.12^{\mathrm{c}}$ \\
\hline \multicolumn{4}{|c|}{ Female clone } \\
\hline $\mathrm{F} 1$ & Lithuania & early & $3.71 \pm 0.08^{b}$ \\
\hline F8 & Lithuania & early & $2.23 \pm 0.14^{\mathrm{fgh}}$ \\
\hline F ELE & Lithuania & late & $2.09 \pm 0.10^{\text {ghi }}$ \\
\hline $\mathrm{F} 2 \mathrm{M} 2$ & Lithuania & medium-early & $1.80 \pm 0.09^{i}$ \\
\hline F9 & Lithuania & medium-early & $2.01 \pm 0.08^{\text {hij }}$ \\
\hline
\end{tabular}

*Means whose are followed by the same letters in column showed no significant difference at $\mathrm{p} \leq 0.01$.

Berries were randomly picked from different plants of each accession at the technical maturity stage, mixed and transported immediately to the laboratory. Technical maturity stage usually starts at the third week of July (early accessions), at the first week of August (medium-early accessions), and at the second week of August (late accessions). The average weight of a berry was measured by using an analytical balance with a precision of $0.01 \mathrm{~g}$ (model DJ-150E, ISHIDA company, Kyoto, Japan). For accession, three replicates of 50 berries were estimated.

Berries were stored at $-80^{\circ} \mathrm{C}$ until analysis. Before analysis, they were lyophilised at $-54^{\circ} \mathrm{C}$ for $48 \mathrm{~h}$ using a Heto LyoLab 3000 lyophiliser (Bad Grund, Germany).

\section{Headspace Solid-Phase Microextraction}

The analyses were performed according to the previous studies of Mota et al. [2012] and Dong et al. [2019] with modifications. One commercial fibre was used to extract volatiles. According to the recommendations of the supplier (Supelco, Bellefonte, Pennsylvania, USA), the fibre coated with PDMS/DVB as a stationary phase and $65-\mu \mathrm{m}$ film thickness are the most adaptable to determine the compounds in the kiwi matrix. Lyophylised berries of each accession were crushed together and approximately $0.3 \mathrm{~g}$ of each sample was loaded in a $10-\mathrm{mL}$ vial and then sealed with a metal 
cap and PTFE/silicone septa (ROTH, Karlsruhe, Germany). The fibre was exposed to the headspace at $50^{\circ} \mathrm{C}$ for $10 \mathrm{~min}$. Afterwards, the fibre was pulled into the hollow needle sheath and the SPME device was removed from the vial and inserted into the injection port of the GC system for thermal desorption at $260^{\circ} \mathrm{C}$ for $1 \mathrm{~min}$. All samples were analysed in triplicate.

\section{Gas Chromatography/Mass Spectrometry analyses}

For HS-SPME analysis, we used a Shimadzu GC-2010 gas chromatograph and mass spectrophotometer GC-MSQP2010, and workstation software GC-MS solution version 2.71 (Shimadzu Corporation, Okayama, Japan). The column used for analyses was an RTX-5MS (30 $\mathrm{m} \times 0.25 \mathrm{~mm} \times$ $0.25 \mu \mathrm{m}$ ) from Restek (Bellefonte, Pennsylvania, USA). The injector port was heated to $260^{\circ} \mathrm{C}$. The carrier gas was helium 5.0 (AGA, Latvia), delivered at a constant flow of $1.5 \mathrm{~mL} / \mathrm{min}$. The oven temperature was set at $50^{\circ} \mathrm{C}$ for $2 \mathrm{~min}$, and then temperature was increased at $8^{\circ} \mathrm{C} / \mathrm{min}$ to $280^{\circ} \mathrm{C}$ and held for $2 \mathrm{~min}$. Ionisation was maintained off in the fifth min. The electron ionisation detector was maintained at $70 \mathrm{eV}$. A scan was used from 40 to $400 \mathrm{~m} / \mathrm{z}$.

A comparison of MS fragmentation pattern with those of pure compounds and mass spectrum database was performed using the National Institute of Standards and Technology (NIST) MS 08 spectral database. The accessions were grouped according to the flavouring VOCs based on the data from the TGSC Information System (http://www.thegoodscentscompany.com).

\section{Statistical analysis}

Data for different classes of VOCs were processed using the Tableu 9.3.0 (Tableau Software, Seattle, Washington,
USA). The concept horizontal bar plot was adapted with the intent to be clearer, and differences to be more visible [Jones, 2014]. To present the diversity of VOCs, peak areas of GC-MS separations were used. R statistical computing environment [R Core Team, 2020] was used for clustering analysis of A. kolomikta accessions, i.e. packages hclust function and Ward D2. The dendrogram revealed relationships among the accessions according to the content of VOCs. Duncan's multiple range test was used to compare mean values of berry weight based on ANOVA at $\mathrm{p} \leq 0.01$ (R software environment).

\section{RESULTS AND DISCUSSION}

VOCs belonging to eight different classes have been identified in berries of A. kolomikta. We classified these VOCs from a chemical point of view as terpenes, esters, alcohols, aldehydes, anhydrides, diazoles, hydrocarbons, and ketones. In total, 89 VOCs were detected in berries of different $A$. kolomikta accessions, i.e. terpenes (11), esters (30), alcohols (10), aldehydes (3), anhydrides (3), diazoles (1), hydrocarbons (19), and ketones (12). The statistical analysis of VOCs belonging to the different classes was accomplished by peak area and peak height and showed the distribution of these compounds as well as confirmed the separation of six compounds attributed to esters, terpenes, and ketones (Figure 1).

While numerous studies have been done to substantiate the diversity of volatile compounds in other species of Actin$i d i a$, this study reports that berries of different A. kolomikta accessions were also distinguished by a variety of VOCs. The composition of VOCs was specific to different accessions and varied strongly (Figures 2-6). The greatest diversity of VOCs, namely representatives of seven chemical classes, was determined in berries of the female clone F1, the cul-

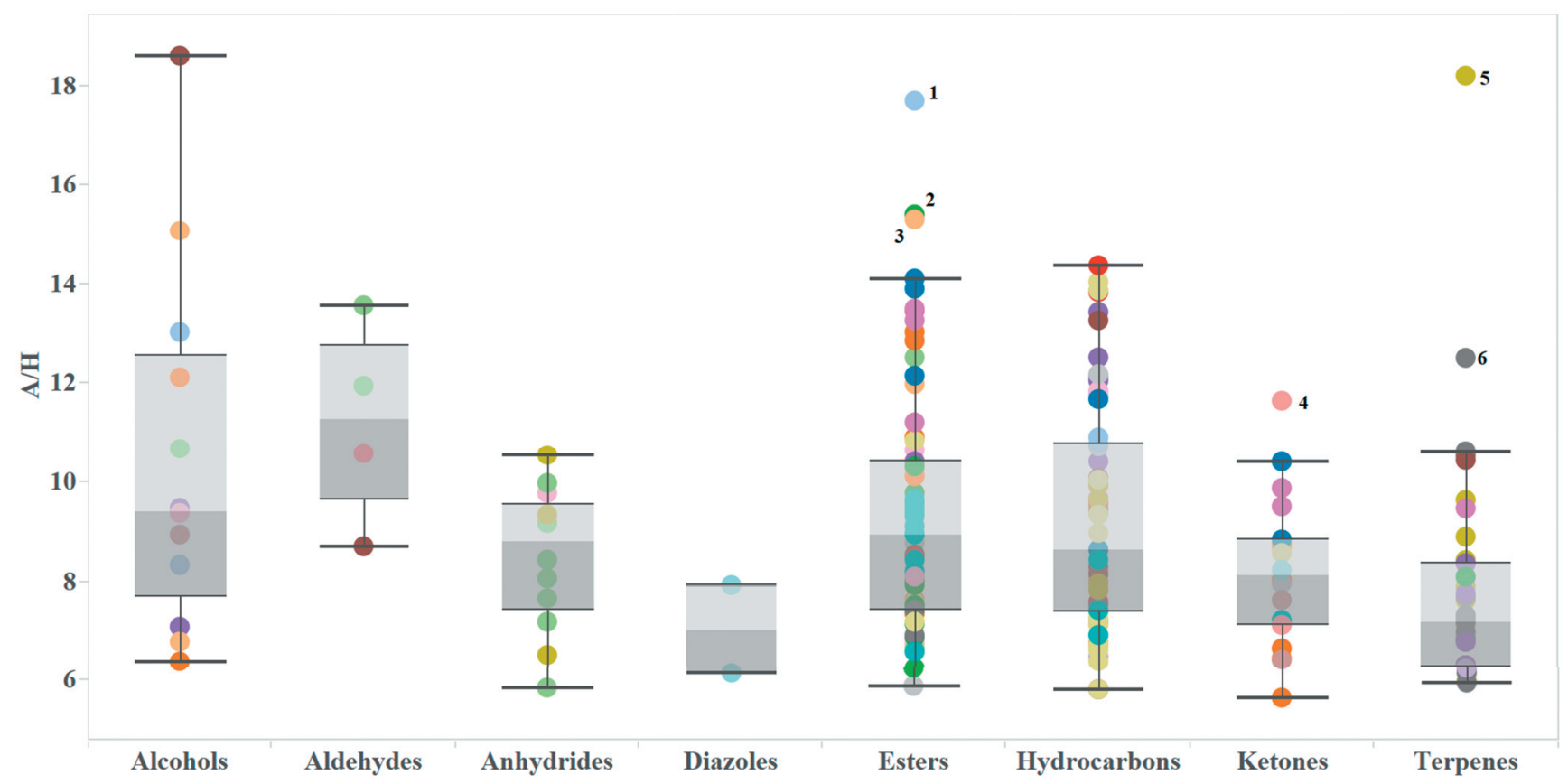

FIGURE 1. Different classes of VOCs according peak area (A) and peak height $(\mathrm{H})$ ratio in berries of A. kolomikta. Outlying VOCs: 1 - oxalic acid, cyclobutyl heptyl ester; 2 - oxalic acid, heptyl propyl ester; 3 - oxalic acid, isobutyl pentyl ester; 4 - 6-methyl-5-hepten-2-one; 5 - 3,5,5-trimethyl-1-hexene; 6 - 3,5-dimethyl-1-hexene. 
Sulfurous acid, pentyl undecyl ester

Sulfurous acid, nonyl pentyl ester

Sulfurous acid, isohexyl pentyl ester

Sulfurous acid, hexyl octyl ester Sulfurous acid, 2-ethylhexyl isohexyl ester

Sulfurous acid, 2-ethylhexyl hexyl ester

Propionic acid, allyl ester

Phthalic acid, cyclobutyl isobutyl ester

Phthalic acid, cyclobutyl ethyl ester

Phthalic acid, butyl 2-pentyl ester

Phthalic acid, 6-ethyl-3-octyl butyl ester

Oxalic acid, isohexyl neopentyl ester

Oxalic acid, isobutyl pentyl ester

Oxalic acid, heptyl propyl ester

Oxalic acid, dineopentyl ester

Oxalic acid, cyclobutyl heptyl ester

Oxalic acid, butyl propyl ester

Didecyl phosphite

Cyclopropanecarboxylic acid,3-methylbutyl ester

Cyclobutanecarboxylic acid, 3-methylbutyl ester

Carbonochloridic acid, heptyl ester

Butanoic acid, 2-propenyl ester

Benzoic Acid*

Benzoic acid, 3-methylbutyl ester

Benzoic acid, 2-ethylhexyl ester

Acetopyruvic acid ethyl ester

Acetic acid, trichloro-, nonyl ester

Acetic acid, trichloro-, heptyl ester

2-Methylbutyl-isovalerate

2-Furancarboxylic acid, 2-methylbutyl ester

1,2-Benzenedicarboxylic acid, butyl octyl ester

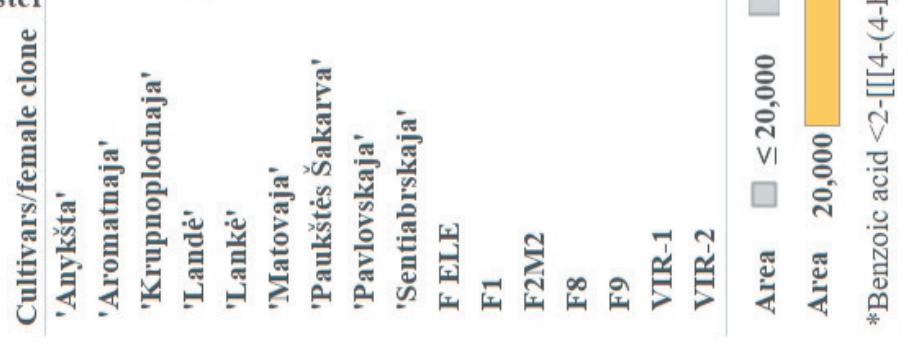




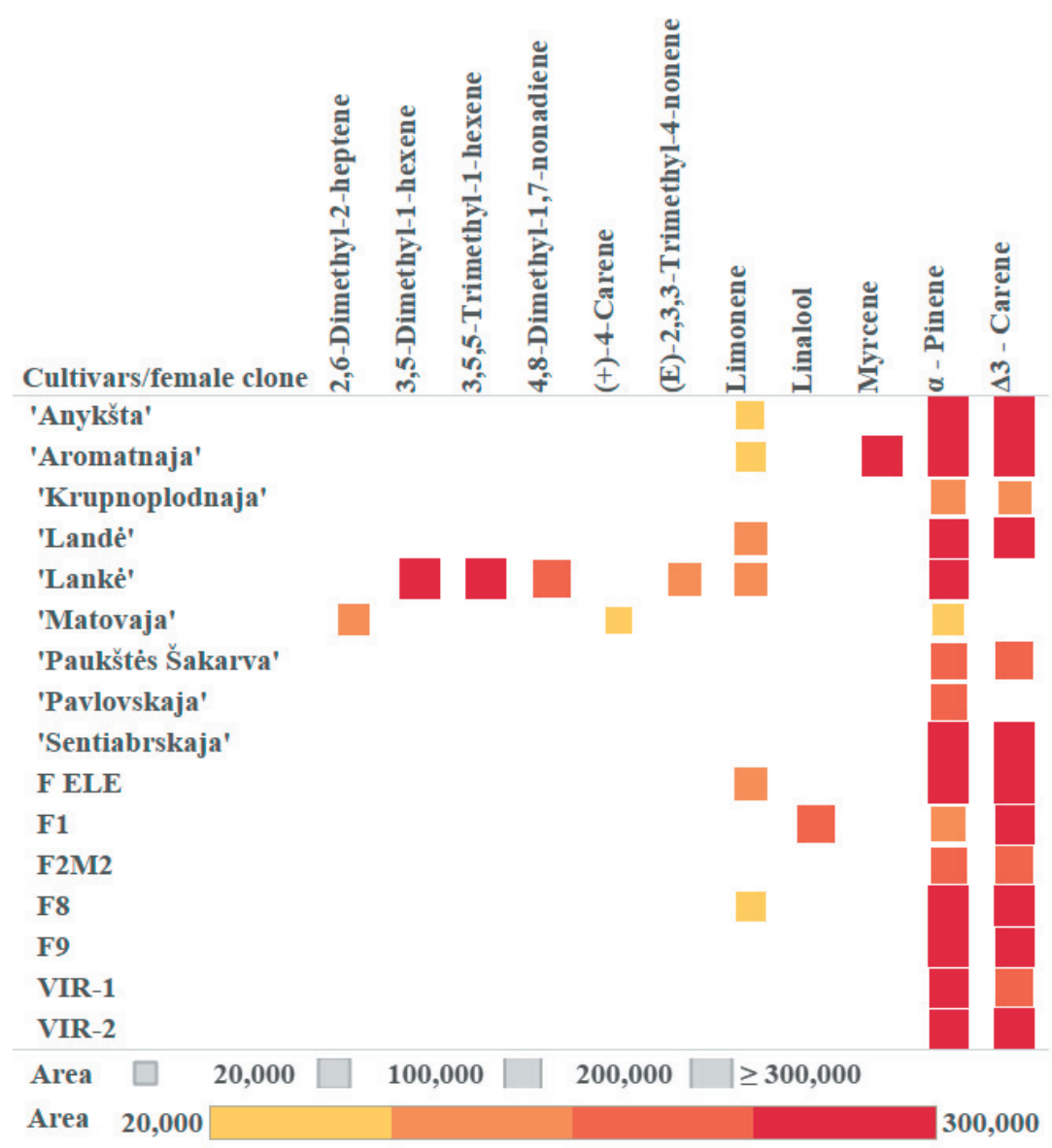

FIGURE 3. Diversity of terpenes in berries of $A$. kolomikta accessions. The size and the colour intensity of squares indicate the content of terpenes.

tivars 'Lankè' and 'Paukštès Šakarva', while the cultivar 'VIR-1' accumulated the smallest number of VOCs classes (four classes). The largest number of different VOCs accumulated was found for the Lithuanian cultivar 'Landè' - 23 compounds and for the Russian cultivar 'Matovaja' - 20 compounds. Berries of both cultivars were also distinguished by a great variety of VOCs classes, including hydrocarbons, terpenes, alcohols, ketones, and esters. A. kolomikta accessions contained from one ('Pavlovskaja') to eight (F2M2 and F9) esters, from one ('Pavlovskaja') to six ('Lankè) terpenes, and from one (cultivars 'Anykšta', 'Aromatnaja', 'Krupnoplodnaja', 'Paukštės Šakarva', F8, F ELE) to six ('Landè') ketones. Berries of the cultivar 'VIR-1' did not accumulate hydrocarbons, whereas VOCs belonging to the alcohols were not detected in berries of cultivars 'Aromatnaja', 'Sentiabrskaja', 'VIR-1' and clones F8 and F9. The diversity of aldehydes and anhydrides was not significant, i.e. these VOCs were found in berries of three accessions. Other authors determined more aldehydes in A. arguta and A. deliciosa [Garcia et al., 2012b; Matich et al., 2003]. In turn, berries of cultivars 'Krupnoplodnaja' and 'Paukštès Šakarva' accumulated $1 H$-imidazole from diazoles class.

Esters were the most abundant class of VOCs in the accessions of $A$. kolomikta (Figure 2). For example, benzoic acid $<2$-[[[4-(4-hydroxy-4-methylpentyl)-,3-cyclohexene-1-yl] methylene]amino]-,methyl- $>$ ester was the most common be- cause it was determined even in thirteen accessions. Its highest content was determined for the accessions F ELE, 'Anykšta', F1 and F9. Matich et al. [2003] reported ethyl butanoate, hexanoate, 2-methylbutanoate, and 2-methylpropanoate among the the most common esters in the berries of A. arguta. In turn, Crowhurst et al. [2008] confirmed butyl acetate to be the major ester in A. eriantha that was responsible for a pineapplelike aroma. Benzoic acid, 2-ethylhexyl ester was common enough, however, its peak areas were considerably smaller. The highest content of carbonochloridic acid heptyl ester was found in the cultivar 'Lankè' whose berries were unique for oxalic acid, izobutyl pentyl ester and sulphurous acid, 2-ethylhexyl hexyl ester. Relatively small contents were characteristic of the unique esters, namely 1,2-benzenedicarboxylic acid, butyl octyl ester and acetoperuvic acid ethyl ester ('Lande'). Six esters of sulphurous acid were separated and four of them, i.e. 2-ethylhexyl ester, isohexyl pentyl ester, nonyl pentyl ester, and pentyl undecyl ester, were unique to the accessions 'Lande', 'Anykšta', 'Matovaja' and F2M2, respectively. Sulphurous acid, 2-ethylhexyl isohexyl ester was the most common of sulphurous acid esters. Arulkumar et al. [2018] found that this ester had characteristic antimicrobial and antioxidative properties, which were demonstrated in the in vitro experiments. Wang et al. [2011] have reported that sulphur compounds were found in gold kiwifruit ('Hort16A') and could to be one of the most important contributors to the flavour of this cultivar. 


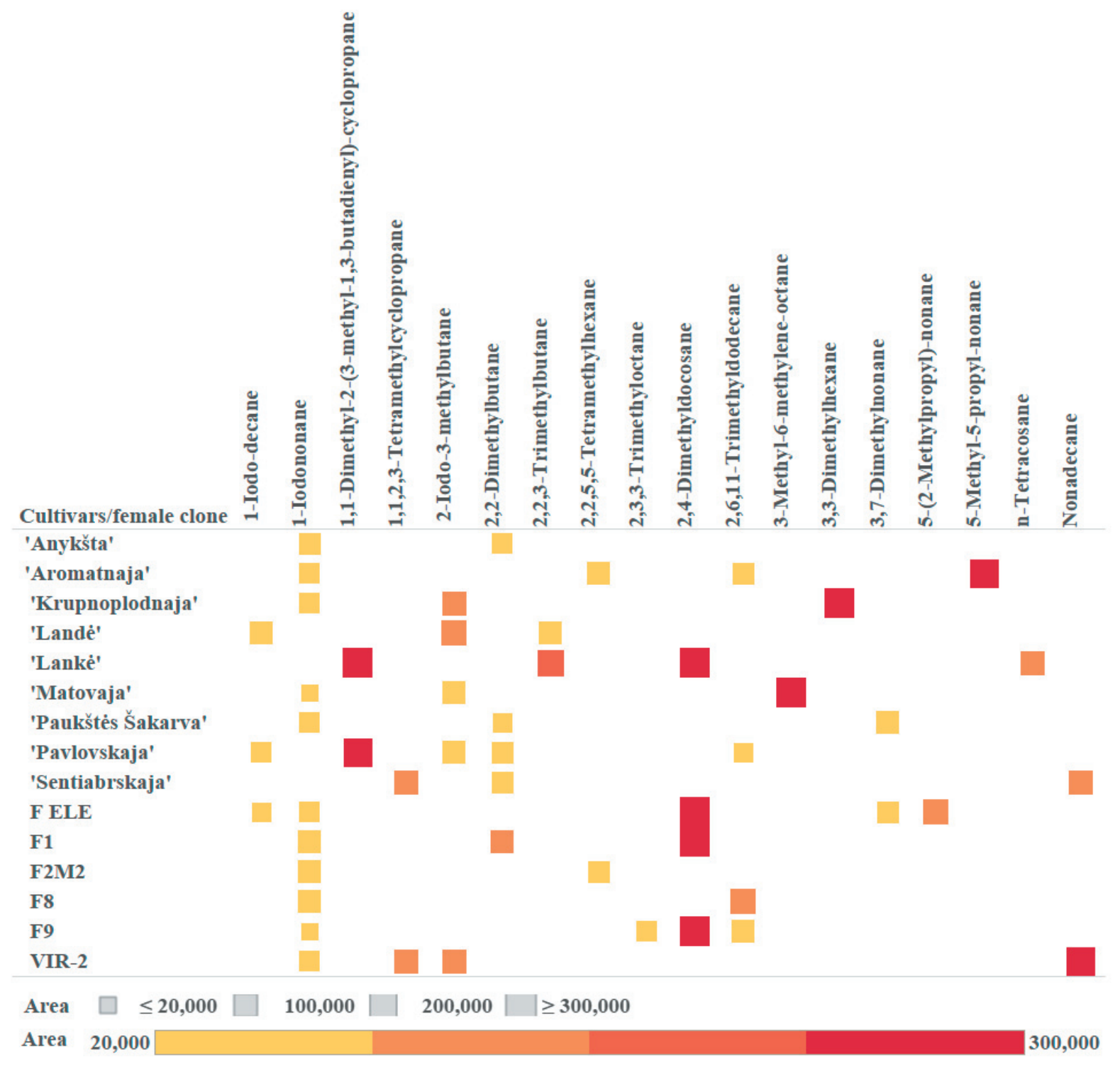

FIGURE 4. Diversity of hydrocarbons in berries of $A$. kolomikta accessions. The size and the colour intensity of squares indicate the content of hydrocarbons.

Rodríguez et al. [2013] reported that ester fraction is the main contributor to the aroma of different fruits. Our results confirmed esters as the most abundant class of VOCs because they were found in berries of all accessions investigated. Other authors have determined esters to be one of the main classes of VOCs in berries of A. deliciosa and A. chinensis [Garcia et al., 2012b; Matich et al., 2003] and illustrated their impact on the characteristic flavours of different Actinidia species [Henare, 2016; Wang et al., 2011]. Our results correspond to the investigations of $A$. arguta where the VOCs identified in its berries mainly consisted of esters [Garcia et al., 2011]. Differently from the above-mentioned Actinidia species, alcohols were the most numerously represented VOCs in berries of A. eriantha [Garcia et al., 2012a]. Interestingly, we determined that twenty esters out of the thirty found were accession-specific (Figure 2).

Berries of A. kolomikta accessions accumulated different levels of $\alpha$-pinene, a terpenes class compound (Figure 3). Other terpene, $\Delta^{3-}$-carene, was common also and it was found in most of the accessions. In terms of the distinctness of the accessions studied, the cultivar 'Lankè' was exceptional due to the highest variety of terpenes. The smallest amounts were characteristic of (+)-4-carene which was unique to the cultivar 'Matovaja'. The VOCs $\alpha$-pinene, $\Delta^{3}$-carene, and limonene were more common compared to other terpenes, which were found only in individual accessions investigated. Matich et al. [2003] reported $\alpha$-pinene, limonene, and linalool in A. arguta berries which is in agreement with our results. Terpenoids were referred as the most abundant VOCs for the A. deliciosa cultivar 'Hayward' also [Garcia et al., 2013]. Nieuwenhuizen et al. [2010] noted terpenes as very important secondary metabolites and emphasized their essential role in plants interacting with the biotic environment, including pollinator attraction, direct and indirect defence against insects, bacteria, and fungi. Other studies confirmed that terpenes demonstrate antioxidant and antidiabetic properties as well as antimicrobial or antifungal activities [Kupska et al., 2016; Wang et al., 2008]. 


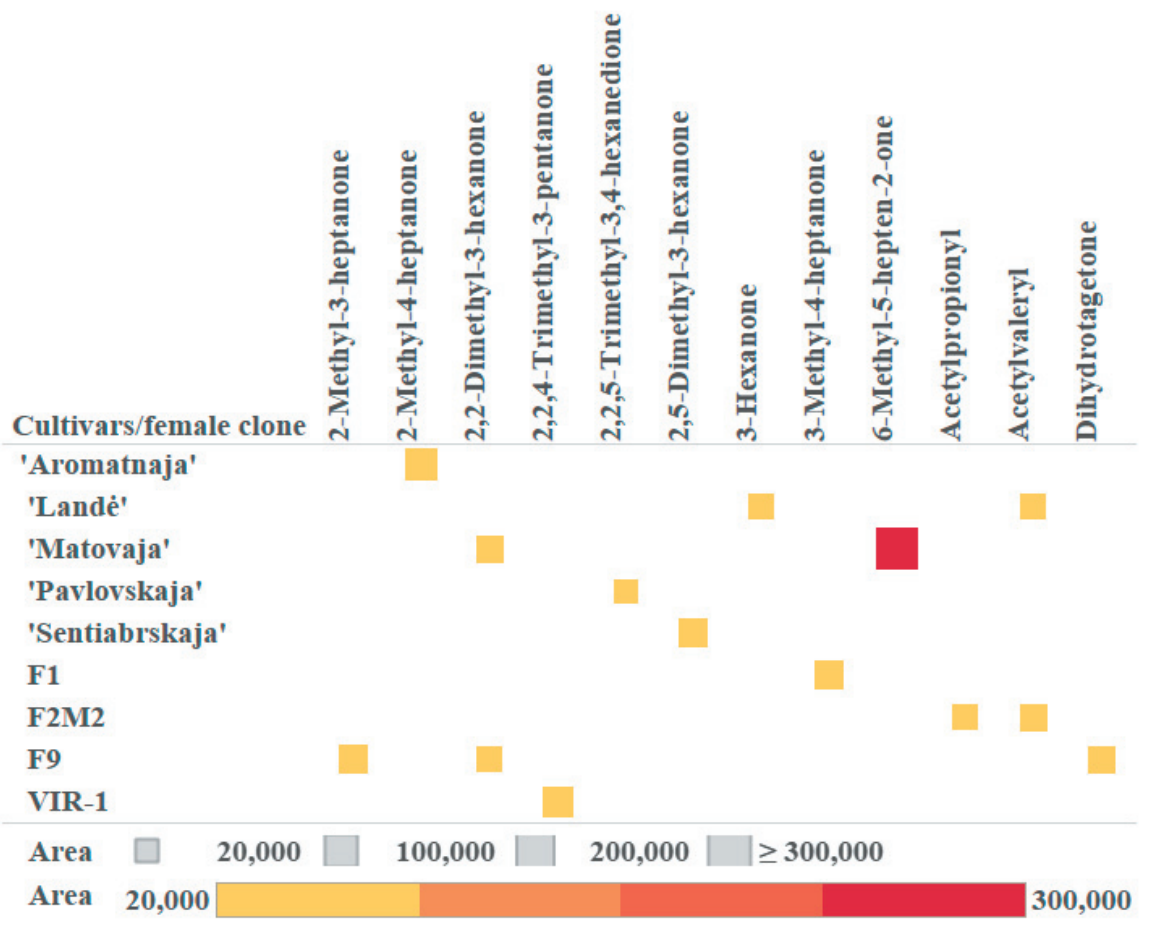

FIGURE 5. Diversity of ketones in berries of A. kolomikta accessions. The size and the colour intensity of squares indicate the content of ketones.

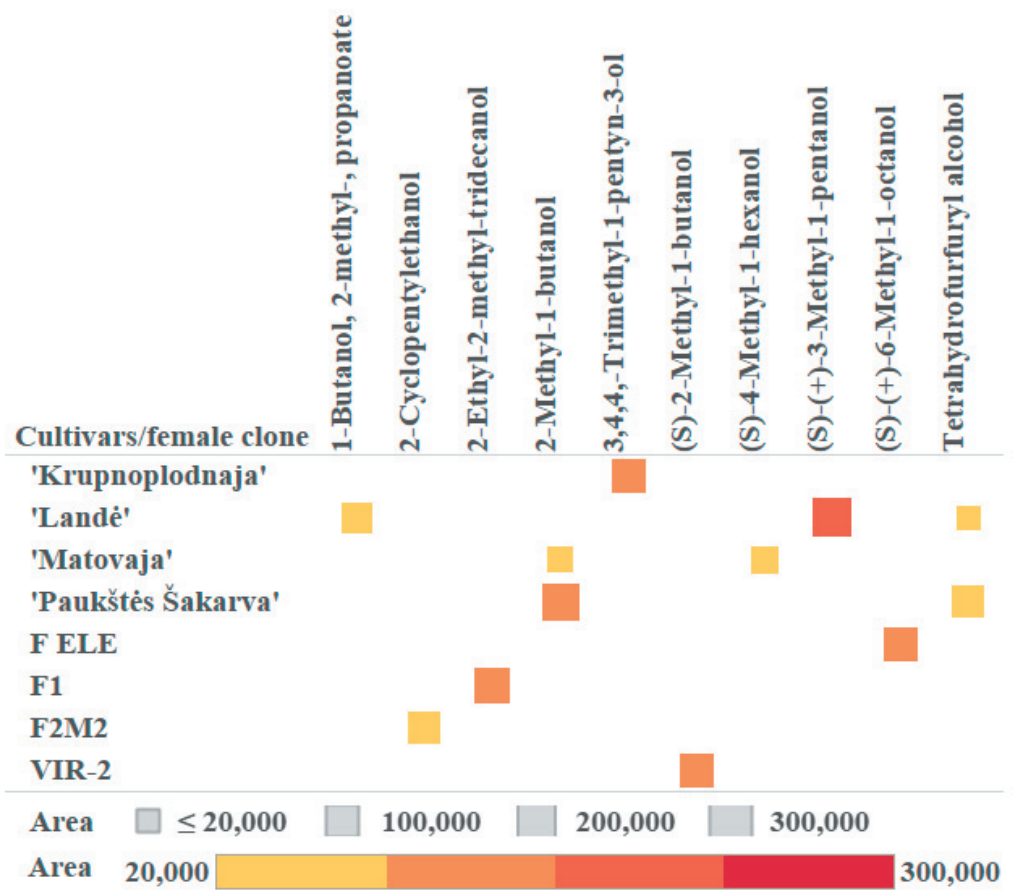

FIGURE 6. Diversity of alcohols in berries of A. kolomikta accessions. The size and the colour intensity of squares indicate the content of alcohols. 


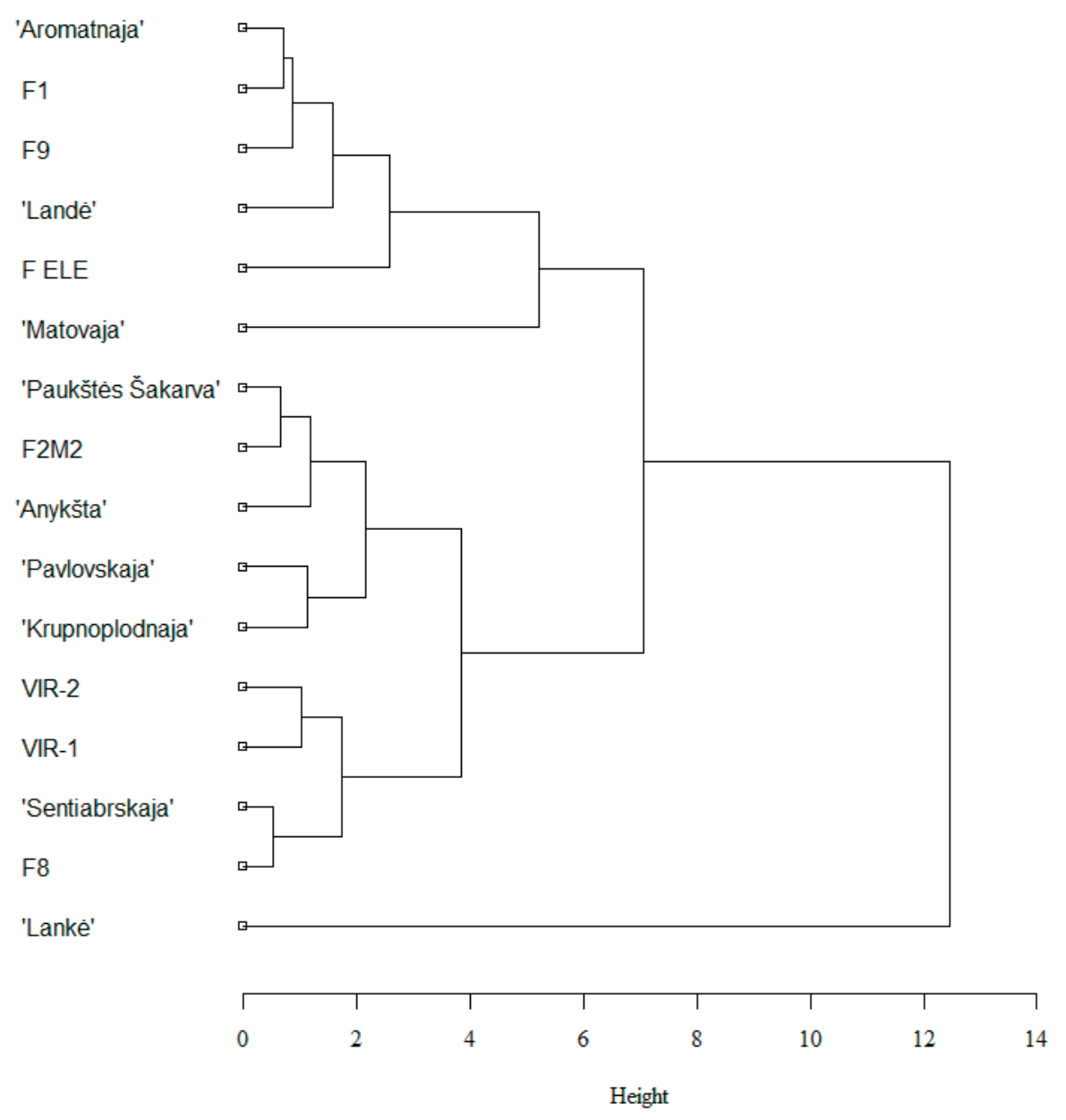

FIGURE 7. Similarity of cultivars and female clones of A. kolomikta depending on the content of VOCs

The hydrocarbons 1-iodononane; 2-iodo-3-methylbutane; 2,2-dimethylbutane; 2,6,11-trimethyldodecane and 2,4-dimethyldocosane were common in berries of $A$. kolomikta (Figure 4). Other hydrocarbons were accession-specific. Interestingly, no hydrocarbons were determined in berries of the Russian cultivar 'VIR-1'.

Ketones were detected in all samples at much lower levels whereas the cultivar 'Matovaja' was characterised by the high content of 6-methyl-5-hepten-2-one (Figure 5). Alcohols were found in berries of eight accessions (Figure 6). Our results have shown that the majority of ketones and alcohols were unique and have been found in one particular accession, but not in the others.

The dendrogram of $A$. kolomikta accessions was constructed and revealed the similarity of cultivars and female clones according to the content of VOCs (Figure 7). The fifteen accessions were classified into two main clusters and the cultivar 'Lanke' was distinctly separated from all the other accessions due to its unique VOCs. This cultivar accumulated several unique volatiles (four esters, four terpenes, and one hydrocarbon) and no alcohols and ketones. The high similarity comparing VOCs composition was determined for 'Sentiabrskaja' and F8 for 'Paukštès Šakarva' and F2M2 as well as for 'Aromatnaja' and F1.

The quantitative and qualitative composition of VOCs depends not only on the genotype properties but also on ex- traction and detection methods. The composition of volatiles in berries of Actinidia species have been analysed by different authors using different methods, so this can cause some differences in the results obtained. For comparative reasons, we have created a diagram which is based on the data obtained from TGSC information system and studies of other authors [Garcia et al., 2012a; Garcia et al., 2013; Lindhorst $\&$ Steinhaus, 2016]. We grouped the accessions of $A$. kolomikta according to the tentative aroma active compounds (Figure 8). Benzoic acid <2-[[[4-(4-hydroxy-4-methylpentyl)-,3cyclohexene-1-yl]methylene]amino]-,methyl-> ester; benzoic acid, 2-ethylhexyl ester; $\alpha$-pinene; $\Delta^{3}$ - carene, and butanoic acid anhydride were ascertained as the main constituents of $A$. kolomikta berry aroma.

Summarizing the results, it can be stated that both a high variety of VOCs and unique compounds were characteristic of $A$. kolomikta berries. Successful use of these berries in human nutrition depends on their flavour properties, which are coherent with quantitative and qualitative composition of VOCs.

Some of these compounds have already been investigated for their effects on human health [An et al., 2016; Drummond, 2013; McGhie, 2013] and berry pleasantness [Jiang \& Song, 2010; Negre-Zakharov et al., 2009; Rodríguez et al., 2013]. On the other hand, emission of VOCs by berries is related to a wide range of ecological functions, including their 


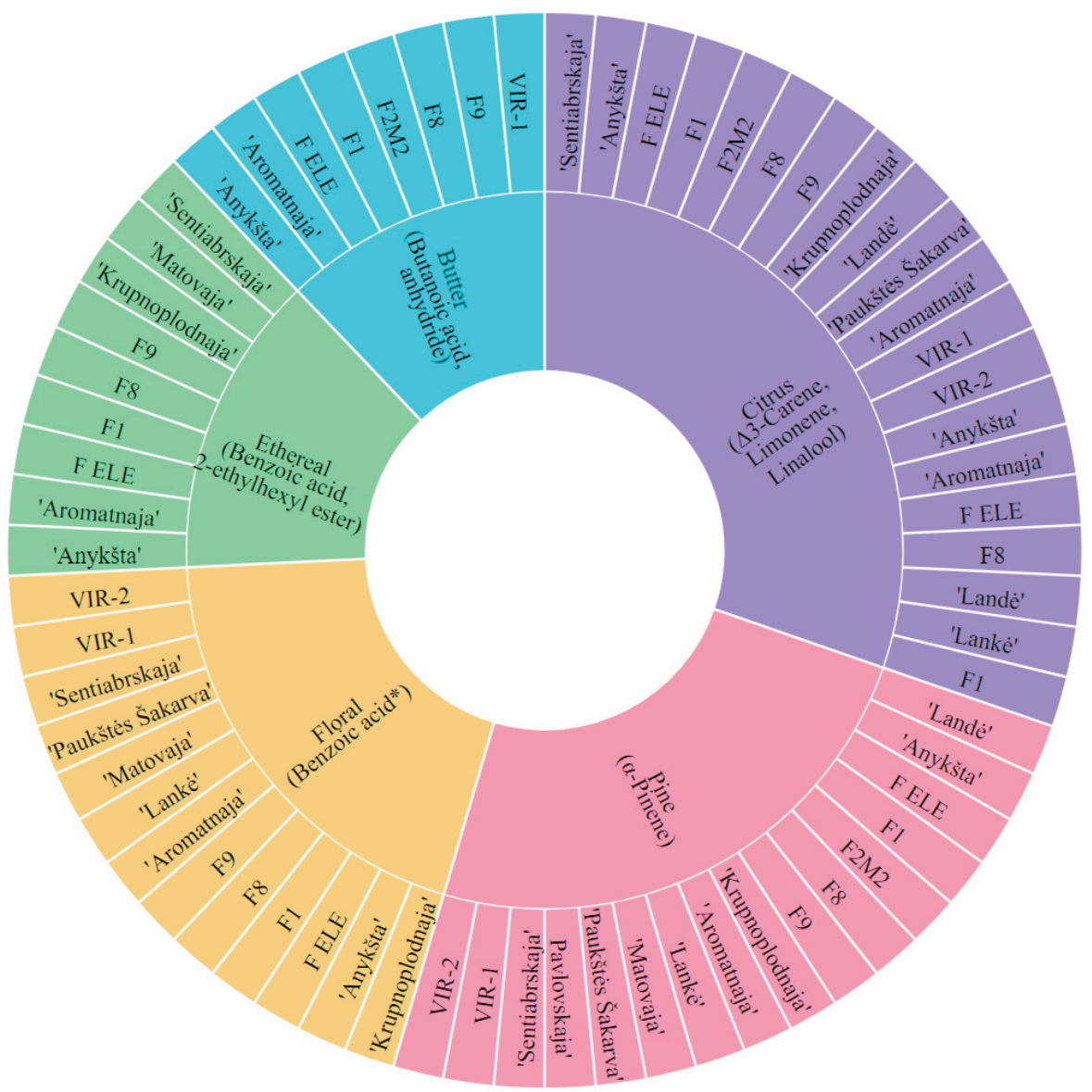

FIGURE 8. The flavour compounds in berries of $A$. kolomikta accessions.

Benzoic acid* - benzoic acid <2-[[[4-(4-hydroxy-4-methylpentyl)-,3-cyclohexene-1-yl]methylene]amino]-,methyl->ester.

role in interacting with pests or microbes [Dudareva et al., 2006]. These affirmations provide the basis for more intensive use of $A$. kolomikta berries not only in food but also in pharmaceutical and cosmetic industries. Further studies on the VOCs accumulated in berries of $A$. kolomikta should focus on the biological activities of these important secondary metabolites.

\section{CONCLUSIONS}

Investigation of sixteen accessions of $A$. kolomikta revealed the large quantity of VOCs accumulated in berries. All identified compounds were classified as esters, alcohols, hydrocarbons, terpenes, aldehydes, anhydrides, ketones, and diazoles. This study has demonstrated that esters are the most abundant class of VOCs in berries of A. kolomikta. While some VOCs are common to almost all accessions, other compounds are specific to only one or a few cultivars or female clones. The accessions $\mathrm{F}_{1}$, 'Lankè', and 'Paukštès Šakarva' accumulated a large variety of VOCs classes while berries of the cultivars 'Landè' and 'Matovaja' were distinguished by the highest levels of VOCs. The species A. kolomikta has a great potential to be considered as a highly valuable source of VOCs which determine the attractiveness of specific cultivars or female clones for consumers. The diversity of VOCs contributing to the flavour of berries is particularly important for the breeding of new cultivars with more attractive and useful properties.

\section{ACKNOWLEDGEMENTS}

We express our gratitude to the team of the Instrumental Analysis Open Access Centre of Vytautas Magnus University for assistance carrying out chemical analyses.

\section{REFERENCES}

1. An, X., Lee, S.G., Kang, H., Heo, H.J., Cho, Y.-S., Kim, D.-O. (2016). Antioxidant and anti-inflammatory effects of various cultivars of kiwi berry (Actinidia arguta) on lipopolysaccharidestimulated RAW 264.7 cells. Journal of Microbioly and Biotechnology, 26(8), 1367-1374.

2. Arulkumar, A., Rosemary, T., Paramasivam, S., Rajendran, R.B. (2018). Phytochemical composition, in vitro antioxidant, antibacterial potential and GC-MS analysis of red seaweeds (Gracilaria corticata and Gracilaria edulis) from Palk Bay, India. Biocatalysis and Agricultural Biotechnology, 15, 63-71.

3. Cheng, C.H., Seal, A.G., MacRae, E.A., Wang, M.Y. (2011). Identifying volatile compounds associated with sensory and fruit attributes in diploid Actinidia chinensis (kiwifruit) using multivariate analysis. Euphytica, 181(2), 179-195. 
4. Chesoniene, L. (2000). Comparison of some biological features and fruiting potential of Actinidia kolomikta cultivars. Acta Horticulture, 538(2), 769-774.

5. Chesoniene, L., Daubaras, R., Viskelis, P. (2004). Biochemical composition of berries of some kolomikta kiwi (Actinidia kolomikta) cultivars and detection of harvest maturity. Acta Horticulture, 663(1), 305-308.

6. Crowhurst, R., Gleave, A., MacRae, E., Ampomah-Dwamena, C., Atkinson, R., Beuning, L., Bulley, S.M., Chagne, D., Marsh, K.B., Matich, A.J., Montefiori, M., Newcomb, R.D., Schaffer, R.J., Usadel, B., Allan, A.C., Boldingh, H.L., Bowen, J.H., Davy, M.W., Eckloff, R., Ferguson, A.R., Fraser, L.G., Gera, E., Hellens, R.P., Janssen, B.J., Klages, K., Lo, K.R., MacDiarmid, R.M., Nain, B., McNeilage, M.A., Rassam, M., Richardson, A.C., Rikkerink, E.H.A., Ross, G.S., Schröder, R., Snowden, K.C., Souleyre, E.J.F., Templeton, M.D., Walton, E.F., Wang, D., Wang, M. Y., Wang, Y.Y., Wood, M., Wu, R., Yauk, Y.-K., Laing, W.A. (2008). Analysis of expressed sequence tags from Actinidia: applications of a cross species EST database for gene discovery in the areas of flavor, health, color and ripening. BMC Genomics, 9(1), art. no. 351 .

7. Dong, S., Bi, H., Zheng, D., Li, Y., Zhao, Y., Peng, W. (2019). Analysis of biodrugs extracted from kiwi fruit by FT-IR and GC-MS. Journal of Environmental Biology, 40(3), SI, 509-514.

8. Drevinskas, T., Naujokaityte, G., Maruška, A., Kaya, M., Sargin, I., Daubaras, R., Česoniené, L. (2017). Effect of molecular weight of chitosan on the shelf life and other quality parameters of three different cultivars of Actinidia kolomikta (kiwifruit). Carbohydrate Polymers, 173, 269-275.

9. Drummond, L. (2013). The composition and nutritional value of kiwifruit. Advances in Food Nutrition Research, 68, 33-57.

10. Dudareva, N., Negre, F., Nagegowda, D.A., Orlova, I. (2006). Plant volatiles: recent advances and future perspectives. Critical Reviews in Plant Sciences, 25(5), 417-440.

11. Garcia, C.V., Quek, S.Y., Stevenson, R.J., Winz, R. (2011). Characterization of the bound volatile extract from baby kiwi (Actinidia arguta). Journal of Agricultural and Food Chemistry, 59(15), 8358-8365.

12. Garcia, C.V., Quek, S.Y., Stevenson, R.J., Winz, R. (2012a). Characterization of bound volatile compounds of a low flavor kiwifruit species: Actinidia eriantha. Food Chemistry, 134(2), 655-661.

13. Garcia, C.V., Quek, S.Y., Stevenson, R.J., Winz, R.A. (2012b). Kiwifruit flavour: A review. Trends in Food Science \& Technology, 24(2), 82-91.

14. Garcia, C.V., Stevenson, R.J., Atkinson, R.G., Winz, R.A., Quek, S.Y. (2013). Changes in the bound aroma profiles of 'Hayward' and 'Hort16A' kiwifruit (spp.) during ripening and GC-olfactometry analysis. Food Chemistry, 137(1-4), 45-54.

15. Henare, S.J. (2016). The nutritional composition of kiwifruit (Actinidia spp.). In Simmonds, M.S.J., Preedy, V.R. (Eds.), Nutritional Composition of Fruit Cultivars, London, Elsevier Inc., pp. 337-370.

16. Jiang, Y., Song, J. (2010). Fruits and fruit flavor: classification and biological characterization. In Hui, Y. H. (Ed.) Handbook of Fruit and Vegetable Flavours, Hoboken, NJ USA, John Wiley \& Sons Inc., pp. 1-23.

17. Jones, B. (2014). Communicating Data with Tableau: Designing, Developing, and Delivering Data Visualizations (1th ed.). Sebastopol, O’Reilly Media, Inc., pp. 69-99.
18. Kupska, M., Wasilewski, T., Jędrkiewicz, R., Gromadzka, J., Namieśnik, J. (2016). Determination of terpene profiles in potential superfruits. International Journal of Food Properties, 19(12), 2726-2738.

19. Latocha, P., Krupa, T., Wołosiak, R., Worobiej, E., Wilczak, J. (2010). Antioxidant activity and chemical difference in fruit of different Actinidia sp. International Journal of Food Sciences and Nutrition, 61 (4), 381-394,

20. Lindhorst, A.C., Steinhaus, M. (2016). Aroma-active compounds in the fruit of the hardy kiwi (Actinidia arguta) cultivars Ananasnaya, Bojnice, and Dumbarton Oaks: differences to common kiwifruit (Actinidia deliciosa 'Hayward'). European Food Research Technology, 242(6), 967-975.

21. Matich, A.J., Young, H., Allen, J.M., Wang, M.Y. Fielder, S., McNeilage, M.A., MacRae, E.A. (2003). Actinidia arguta: volatile compounds in fruit and flowers. Phytochemistry, 63(3), 285-301.

22. McGhie, T. K. (2013). Secondary metabolite components in kiwifruit. Advances in Food and Nutrition Research, 68, 101-124.

23. Mota, L.M., Aguiar, A., Ferreira, I.M.P.L.V.O., Guedes de Pinho, P. (2012). Volatile profiling of kiwifruits (Actinidia deliciosa 'Hayward') evaluated by HS-SPME and GC-IT/MS: Influence of ripening, training system and storage. Food and Bioprocess Technology, 5(8), 3115-3128.

24. Negre-Zakharov, F., Long, M.C., Dudareva, N. (2009). Flora scents and fruit aromas inspired by nature. In A. E. Osbourn, V. Lanzotti (Eds.), Plant-Derived Natural Products, New York, NY, USA, Springer, pp. 405-431.

25. Nieuwenhuizen, N.J., Green, S., Atkinson, R.G. (2010). Floral sesquiterpenes and their synthesis in dioecious kiwifruit. Plant Signaling \& Behavior, 5(1), 61-63.

26. Paulauskienè, A., Tarasevičienè, Ž., Žebrauskienè, A. (2014). Amino acid composition of kolomikta actinidia (Actinidia kolomikta (Maxim. \& Rupr.) Maxim.) fruits of Lithuanian origin. Zemdirbyste-Agriculture, 101(1), 79-84.

27. R Core Team (2020). R: A language and environment for statistical computing. R Foundation for Statistical Computing, Vienna, Austria [http://www.R-project.org/].

28. Rodríguez, A., Alquézar, B., Peńa, L. (2013). Fruit aromas in mature fleshy fruits as signals of readiness for predation and seed dispersal. New Phytologist, 197(1), 36-48.

29. Wang, C.I., Wang, S.I., Chen, C. (2008). Increasing antioxidant activity and reducing decay of blueberries by essential oils. Journal of Agricultural and Food Chemistry, 56(10), 3587-3592.

30. Wang, M.Y., MacRae, E., Wohlers, M., Marsh, K. (2011). Changes in volatile production and sensory quality of kiwifruit during fruit maturation in Actinidia deliciosa 'Hayward' and A. chinensis 'Hort16A'. Postharvest Biology and Technology, 59(1), 16-24.

31. Wang, Y., Zhao, C.L., Li, J.Y., Liang, Y.J., Yang, R.Q., Liu, J.Y., Ma, M., Wu, L. (2018). Evaluation of biochemical components and antioxidant capacity of different kiwifruit (Actinidia spp.) genotypes grown in China. Biotechnology \& Biotechnological Equipment, 32(3), 558-565.

32. Zuo, L.L., Wang, Z.H., Fan, ZL., Tian, S. Q., Liu, J.R. (2012). Evaluation of antioxidant and antiproliferative properties of three Actinidia (Actinidia kolomikta, Actinidia arguta, Actinidia chinensis) extracts in vitro. International Journal of Molecular Sciences 13(5), 5506-5518.

Submitted: 2 April 2020. Revised: 7 May and 5 June 2020. Accepted: 16 June 2020. Published on-line: 7 July 2020. 